\title{
Consideraciones en torno a la clasificación del cuento
}

\author{
M. a Teresa García Ruiz *
}

La investigación sobre el cuento ha consistido durante mucho tiempo en una recopilación de materiales cuyo único objetivo residía en el estudio de las fuentes originales y la comparación con diversos aportes de otros países; se trataba de un trabajo erudito, necesario en tanto nos permite manejar un corpus ya fijado, pero que tiene el peligro de olvidar el principal problema que se plantea al enfrentarnos con el estudio de un fenómeno: la necesidad de describirlo y delimitarlo ya que «on ne peut parler de l'origine d'un phénomène, quel qu'il soit, avant d'avoir décrit ce phénomène» ${ }^{1}$. Asimismo si había algún intento descriptivo del cuento pretendía relacionarlo con otras formas literarias (v. g., la novela) sin tener en cuenta que no se puede estudiar un fenómeno a partir de otros sino a partir de sí mismo - de lo que se desprende lo aventurado que resulta relacionar el cuento con otros géneros literarios si la estructura de éste no está plenamente delimitada-. Las comparaciones deben venir a posteriori y una vez que se conoce objetivamente la clase de material que se maneja. En esta misma línea se sitúan los trabajos de Baquero Goyanes ${ }^{2}$ quien opina que los temas y asuntos encarnables en forma de cuento no suelen admitir ampliación novelesca en un plano semejante a la conjunción perfecta y armónica de una sinfonía, mientras que el cuento es una sola vibración emocional. Del mismo modo, Edgar Allan Poe ${ }^{3}$, insiste en que un cuento gira en torno a un efecto único a partir del cual se inventarán los más variados incidentes que contribuyan a resaltar,

\footnotetext{
* Dpartamento de Literatura. Colegio Universitario de Huesca.

1. Propp, V.: Morphologie du conte, Poétique, Editions du Seuil, 1965, 1970,

2. Baquero Goyanes, M.: Qué es el cuento, Editorial Columba, Colección Esquemas, Buenos Aires, 1967.

3. apud Alba Omil y A. Pienola, R.: El cuento y sus claves, Editorial Nova, Buenos Ãires, 1969.
} pág. 11. 
reforzándolo, el motivo central. Emilio Carilla ${ }^{4}$, se afirma en la tesis de que intensidad y final inesperado son las dos características del cuento; también Eichembaum ${ }^{5}$ se manifiesta de forma similar, al interpretar el cuento como un enigma y a la novela como una charada o un jeroglífico.

Dejaremos a un lado estas teorías, en primer lugar porque pensamos que la distinción entre novela y cuento ha de hacerse partiendo de un estudio sistemático y profundo, alejado de todo intuitivismo engañoso y sometido a fluctuaciones dado que los juicios valorativos dependen de la sensibilidad personal del crítico. Sería más interesante la comparación entre dos estructuras abstractas entresacadas de la observación de un corpus que nos permitiría establecer un sistema de interrelaciones basado en semejanzas y desemejanzas. En segundo lugar, nos parece obvio que la distinción entre cuento y novela tampoco puede residir en la mayor o menor extensión de los temas, lo que resulta a todas lüces comprobable. Propp ya trató en el estudio del cuento maravilloso la existencia de unos elementos auxiliares «servant de liaisons entre les fonctions... qui ont une gran importance, bien qu'ils ne déterminent pas le déroulement de l'intrigue» ${ }^{6}$. Posteriormente Barthes ${ }^{7}$ alude a la existencia de funciones distribucionales y unidades de naturaleza integradora, llamando a estas últimas indicios; las primeras serán funciones cardinales o núcleos y las segundas, catálisis.

Debemos aceptar con Barthes que el cuento popular, groso modo, aparece como algo marcadamente funcional, característica inherente a la tradición popular que mantiene unos rasgos constantes transmitiéndolos de narrador a narrador, mientras que otros datos se cambian o difuminan sometiéndose a una intensa reelaboración. Claro que tanto en el cuento como en la novela hallaremos estos núcleos e indicios necesarios a todo sistema semántico y sintáctico en el que, lógicamente, existen elementos aglutinantes o copulativos y núcleos narrativos. Lo que no resultaría viable sería la utilización de las funciones claves de una novela para la creación de un cuento - al menos sistemáticamente como piensan algunos críticos- superponiendo en un mismo plano narrativo estructuras que sólo de modo gratuito pueden coincidir.

En cuanto a los intentos clasificatorios del cuento aludiremos sólo superficialmente al intento de Aarne-Thompson ${ }^{8}$ y posteriormente éste

4. Carilla, E.: El cuento fantástico, Editorial Nova, Buenos Aires, 1968.

5. Eichembaum, B.: "Sobre la teoría de la prosa», Teoría de la literatura de los formalistas rusos, Ediciones Signos, Buenos Aires, 1970.

6. Op. cit., p. 86.

7. Barthes, R.: “Introducción al análisis estructural de los relatos», Análisis estructural del relato, Editorial Tiempo Contemporáneo, Buenos Aires, 1970, p. 19.

8. AARne-Thompson: The types of the Folktale, a classification and bibliography, segunda revisión, Helsinki, 1961, F. F. C., núm. 184. 
último $^{9}$, quienes han realizado una labor ingente aunque se centra en un estudio comparatista de las variantes de cada tema en el mundo. Vladimir Propp observa a este respecto que «les sujets (et en particulière ceux des contes merveilleuses) sont liés les uns aux autres para un très proche parenté. On ne peut déterminer où s'achève un sujet avec ses variantes et où commence un autre sujet qu'apres une étude approfondie des sujets des contes et une définition précise du principe qui préside à la sélection des sujets et des variantes ${ }^{10}$.

Propp realiza una inteligente crítica al método seguido por estos dos investigadores si bien reconoce que su aportación recopiladora ha rendido un gran servicio al estudio del cuento. Alude Propp a otras clasificaciones entre ellas las de Volkov y Afanaseiv que nos han resultado inaccesibles. En español poseemos la ya clásica de Aurelio Espinosa ${ }^{11}$ que abarca material recogido por toda la península. Aparte contamos con innumerables compilaciones de cuentos adscritos a una límites regionalistas y que no aportan ningún estudio crítico de especial interés ${ }^{12}$.

Un proyecto ambicioso fue el de Menéndez Pidal ${ }^{13}$ que en su antología de cuentos universales pretendía fusionar la mera recopilación con los estudios críticos. Algunas objeciones se pueden señalar a obra de tal magnitud: $1 .^{\circ}$, el criterio de selección es muy amplio, no quedando muy claros los límites del cuento, pues bajo tal denominación se incluyen los elementos más heterogéneos; $2 .^{\circ}$, la recopilación se ciñe ante todo, como ya indica el título, a textos literarios, lo que si en algunos casos en que no se poseen ediciones (v. g., la Disciplina Clericales de Pedro Alfonso aparece íntegramente traducida) resulta muy grato, en otros (Patrañuelo, Decamerón, etc.), carece de interés. Por el contrario, se ha evitado la inclusión de cuentos populares recogidos de la tradición oral a los que sólo se dedica un capítulo. Claro que hemos llegado a un punto en que podríamos preguntarnos qué es popular; ¿es que los cuentos conocidos

9. Thompson, S.: Motif-Index of Folk-Literatura, segunda edición, Copenhague, Rosenkil-de \& Bagger, 1955-1958, 6 vol.

10. Op. cit., p. 17 .

11. Espinosa, A.: Cuentos populares españoles, recogidos de la tradición oral de España, C.S.I.C., Instituto “Antonio de Nebrija», de Filosofía, tres tomos, Madrid, 1946.

12. Citamos algunos de ellos tan solo, pues de lo contrario la lista sería interminable: Cuentistas aragoneses, prólogo de J. García Mercadal, imprenta de Emilio Casanal, Zaragoza, 1910; Ourvan, F.: Cuentos aragoneses (selección) Caja de Ahorros de Zaragoza, 1967; Larrea Palacín, A.: Cuentos gaditanos, C.S.I.C., Centro de Estudios de Etnología Peninsular, Madrid, 1959; BAselga, M.: Cuentos aragoneses, Institución “Fernando el Católico» (C.S.I.C.), de la Excma. Diputación Provincial de Zaragoza; Cuentos de la vieja España, Estudio preliminar de F. Sáinz de Robles, Aguilar, Madrid, 1964; Manrique DE LARA: Leyendas y cuentos populares españoles, Editorial Bruguera, Barcelona, 1971, etc....

13. Meníndez Pidal, R.: Antología de cuentos de la literatura universal, Editorial Labor, 1955. 
en la tradición y que han sido utilizados por la literatura no son también populares? Efectivamente, pero no cabe duda de que Pidal incluye en su clasificación cuentos ${ }^{14}$ que no tienen vinculación alguna con la tradición y que de algún modo habría que distinguirlos de los otros. En español no poseemos una terminología adecuada para distinguir el cuento propiamente dicho de la «nouvelle» francesa que algunos traducen con el término «novela corta», al que no correspondería exactamente. A este respecto son interesantes las opiniones que Shklovski expone en su artículo "La construcción de la "nouvelle" y de la novela» 15. Debemos soslayar el tratamiento de un problema tan complicado y que seria tema para un estudio que se saldría de los límites restringidos a los que nos ceñimos aquí, sólo apuntaremos la necesidad de establecer una terminología clara y precisa que deslinde las clases de cuentos en particular. Vladimir Propp consiguió un notable avance en el campo de lo maravilloso y Todorov, aunque de modo diferente, en lo fantástico ${ }^{16}$.

Ultimamente la crítica formalista y estructuralista se ha preocupado del estudio del cuento y el relato en general. Partiendo de Propp, al que se considera pionero en esta clase de trabajos, se ha insistido en la simpli. ficación de su método investigador. Naturalmente, resulta más sencillo abstraer sobre un sistema establecido que investigar en un terreno vírgen aunque son indudables las múltiples ventajas que se derivan de una discusión crítica renovadora ${ }^{17}$.

Un subgénero de cuentos que hasta ahora no han gozado de ninguna atención por parte de los estudiosos de la literatura, a no ser de una forma puramente anecdótica, es el de los llamados «picarescos» como los designa Aurelio Espinosa en su clasificación. Se trata de cuentos cuyo núcleo está basado en el engaño del humilde al poderoso y que en cierta medida podrían tomarse como «una manifestación social en la cual el pueblo humilde se queja de su condición servil» ${ }^{18}$. Indudablemente el cuento gira en torno a una situación equívoca en cuyo juego entre engaño y verdad que se apoya en una categoría gramatical fundamental, la de ser vs. parecer, está implícito el oyente. «No se trata de tal o cual receptor particular real,

14. Entre ellos, citamos sólo algunos, vg.: «Mimi Pinson», de Musset; «El miedo», de Guy de Maupassant; “El castellano viejo», de Larra, etc....

15. Sнкцоvsкi, V.: Teoría de la literatura de los formlistas rusos, Ediciones Signos, Buenos Aires, 1970.

16. Todorov, T.: Introducción a la literatura fantástica, Editorial Tiemppo Contemporáneo, Buenos Aires, 1972.

17. Véase: Polémica Levi-Strauss/Propp, V.: Editorial Fundamentos. Cuadernos prácticos núm. 2, Madrid, 1972; Greimas: “Reflexions sur les modêles actanticls», Sémantique structurale, “Langue et Language», Larousse, Paris, 1966.

18. Espinosa, A.: Op. cit., p. 129. 
sino de una función de receptor implícita al texto» ${ }^{19}$. El destinatario sabe que existe una situación engañosa, pero no entra dentro de sus posibilidades determinar el modo cómo se ha de consumar el engaño, de ahí su sorpresa que casi siempre se inclina hacia el lado cómico. Ahora bien, de este tipo de cuentos existen múltiples variantes en las que sólo se mantiene el núcleo central del engaño mientras que su solución cómica varía, v. g., Till Eulenspiegel advierte a sus vecinos que va a volar en el tejado de la alcanldía y después de haber recorrido varias veces el tejado haciendo ademán de volar, dirigiéndose a los espectadores, dijo: «¿Cómo esperáis que vuele por el aire habiendo anunciado yo que volaría en el tejado? He querido averiguar si había memos en esta ciudad». Existe otro cuento muy vinculado a la tradición folklórica oscense, el milagro de Alcolea, en el que Pedro Saputo para reunir una multitud y vender un vino que se tornaba agrio ofrece volar desde lo alto de las Ripas de Alcolea. Tras retener al pueblo durante tres días se burla de ellos, pues haciendo grandes conatos y ademanes de lanzarse al vacío, arrojó con fuerza el gabán y les dijo: «Mirad cómo vuela». Y al mismo tiempo echó a correr.

Evidentemente el engaño es el elemento constante en estos dos cuentos, si bien en el Milagro de Alcolea adquiere una dimensión doble al estar motivado por la venta del vino. Hallamos en éste dos acciones definidas por los verbos vender y volar íntimamente relacionados, pues ambos se valen del engaño para realizarse. La secuencia, formada por la contaminación de dos acciones, presenta una estructura más compleja que la del cuento de Till y por tanto podría ser posterior ${ }^{20}$.

La solución del engaño tiene distinto carácter en una y otra versión. El cuento aragonés presenta una serie de repeticiones que retardan el final creando una situación de suspenso que en cierta medida es una forma de distorsión: al tercer día Saputo subirá a las Ripas y al tercer aviso lanzará el gabán. Sin embargo, el engaño reviste un carácter más ingenioso en Eulenspiegel en tanto que se apoya en una frase de doble sentido cuya presencia rige todo el cuento hasta el punto de que, al final, forzosamente debemos volver a ella y reinterpretarla. La ambigüedad de la frase incial «volar en el tejado», que pasará desapercibida al oyente, será el resorte cómico fundamental que ejercerá un modo de reacción sobre todo el cuento.

Dentro de la clasificación de picarescos, con la que se pretende vincularlos a una determinada tipología literaria, se agrupan cuentos excesivamente diversificados. Además esta denominación conlleva una carga se-

19. Todorov, T.: Op. cit., p. 41.

20. Sobre todo si pensamos en la hipótesis expuesta por la escuela finesa, según la cual si la versión especial o el subtipo es privativo de una sola región, se trata de una tardia recreación del tipo. 
mántica de la que no se puede prescindir fácilmente induciendo a interpretaciones erróneas. Sería más conveniente utilizar el término «burlesco» que no tiene ninguna connotación especialmente marcada y que, además, correspondería más exactamente al núcleo narrativo del cuento centrado en la burla que el más «agudo» infiere al poderoso quien es aparentemente más listo que aquél. A veces este carácter ingenioso está enmascarado y sólo es comprobable en los resultados ventajosos que el necio obtiene mediante acciones absurdas con las que consigue vencer al individuo o grupo social oficialmente considerados como listos. De nuevo nos hallamos ante el juego opositivo ser vs. parecer. Un ejemplo lo tenemos en los cuentos de Juan Listo y Juan Tonto (ver cuento 165), en los que es éste último quien con sus argucias consigue burlarse del amo. Los adjetivos cumplen una función atributiva y mantienen una relación inversa con las acciones que sustentarán. Decir Juan Listo aquivale a «Juan hace cosas listas o inteligentes», mientras que la ejemplificación activa de esa supuesta capacidad corresponde a «Juan hace cosas tontas». Nos hallamos ante una figura retórica, la antífrasis, muy frecuente en los cuentos populares.

Fácilmente se infiere que el agente Juan no posee ningún contenido en sí mismo, puesto que la diferencia entre ellos radica en que Listo vs. Tonto. De una parte es significativo el que los hermanos se llamen igual; de otra lo es también la heterogeneidad de los agentes cuya existencia está determinada por tradiciones localistas o regionalistas. Por lo que los mismos predicados extendidos por toda la península informan a personajes populares como Pedro de Urdemalas, Juan Listo, Juan Tonto; en Huesca Pedro Saputo, etc. Todorov en la Grammaire du recit, afirma que el agente «ne peut être pourvu d'aucune propieté; il est comme une forme vide que viennent a remplir des différents prédicats»; y en la Gramática del Decamerón alude al aspecto denominativo y descriptivo que se halla en el interior de una misma palabra del tipo «el rey de Francia», o «la viuda», o «el criado» ${ }^{21}$. Nos hallamos ante una situación semejante al haberse sustantivado el adjetivo Listo que contiene por ello un valor denominativo y descriptivo al mismo tiempo, en tanto nominaliza y caracteriza a un agente desprovisto de todo valor semántico: Juan. Una objeción podría presentarse a todo esto y es que el nombre Juan posee unos rasgos de generalidad que le otorgan un determinado valor a tener en cuenta. Los nombres más utilizados en la tradición popular son del tipo: Pedro, Juan y María, lo que les hace susceptibles de sustentar cualquier predicado en tanto ellos mismos contienen los atributos inherentes a la vulgaridad.

21. Todorov, T.: Gramática del Decamerón, Taller Ediciones J. B., Madrid, 1973 , p. 53. 
En la clasificación de los llamados cuentos «picarescos» Espinosa distingue cinco subtipos: a) Pedro de Urdemalas; b) Los los compadres; c) El tonto y la princesa; d) Juan Tonto; e) Varios. Esta división presenta varias incongruencias fácilmente comprobables. En principio los grupos se han ordenado según el agente que protagoniza cada cuento, lo que denota una arbitrariedad total ya que como sabemos los agentes pueden variar sin que se registre ningún cambio en el cuento; también se ha seguido un criterio de semejanza en las secuencias, con lo que se consigue of recer un grupo de variantes al lado de cuentos cuya permanencia en el grupo parece harto difícil. Esto ocurre en el grupo primero en el que bajo la denominación Pedro de Urdemalas — que en todo caso albergaría las cinco primeras variantes - se incluyen otros cuyo tema central sigue siendo el engaño aunque aquí se trate de un engaño a un ser sobrenatural, ya sea el demonio o la muerte.

Ahora bien, dentro de este grupo se podrían incluir los del segundo, los dos compadres, pues la única diferencia en la que se basa Espinosa parece ser el hecho de que sean dos los protagonistas, lo que resulta totalmente accesorio en tanto que esa dualidad representa la oposición pobre-rico que hemos hallado en los cuentos anteriores. El grupo $c$ ) que corresponde al «Tonto y la princesa» es a todas luces inadmisible ya que alguno de los cuentos en él incluídos reúne las características inherentes al cuento maravilloso. Así se observa en el 177, «La princesa que nunca se reía», en que el agente entra en poder de tres objetos mágicos otorgados por un personaje ayudante cuya triple intervención es totalmente paralela y repetitiva. Un personaje idéntico en circunstancias paralelas entrega tres objetos diferentes de funciones a veces semejantes. Nos hallamos ante un caso de «Triplement», fenómeno tan reiterado en el cuento poular. Los tres objetos, que en una primera abstracción cumplen una única misión de auxiliar mágico, serán los que sirvan al tonto para logar sus propósitos: conseguir que la princesa ría, misión en la que habían fracasado los más noblies jóvenes. Sin embargo, el cuento no termina ahí, sino que se encadena con un nuevo cambio o ruptura del equilibrio alcanzado: el tonto debe sufrir tres pruebas para casarse con la hija del rey, lo que supondrá una nueva secuencia. Entendemos por secuencia una serie de oraciones que constituyen una estructura acabada, susceptible de formar por sí sola una historia independiente ${ }^{22}$. Un cuento, por lo demás, puede contener varias secuencias sin perder por ello la unidad. Greimas define la secuencia como «une unité du discours narratif autonome, susceptible de fonctionner comme un récit, mais pouvant ègalement être integrée comme une de ces parties constitutives, dans un récit plus large» ${ }^{23}$.

22. Todorov, T.: Op. cit., p. 40.

23. GreImas, A. J.: «La structure des actants du rècit (Essai d'approche générative) Linguistic Studies presented to André Martinet, Word, 1967, p. 224. 
Aurelio Espinosa tampoco ha visto claramente el papel narrativo de la secuencia hasta tal punto que en el primer grupo de su clasificación a la que denomina cuentos humanos varios, ha incluído un subgrupo de «cuentitos y chistes» en los que se insertan cuentos de la misma estructura que los llamados «picarescos» pero que poseen una sola secuencia. Así ocurre en el cuento $53, \ll E I$ santo del sastre», en el que el aprendiz se venga del olvido del amo. Observamos exactamente igual que en el cuento «Pedro el de Malas» (163) la oposición amo-criado y el triunfo de éste mediante un ardid. El daño inicial procede siempre del amo quien, consciente o inconscientemente, desea castigar al criado pero éste actúa como personaje reflectante devolviendo el daño y venciendo sobre el poderoso. El cuento 163 reúne una serie de secuencias que por sí solas han formado cuentos. Aludiremos sólo como ejemplo a la secuencia en que Pedro engaña a su amo y vende los cerdos que le había encomendado; para hacerle creer que se le han hundido clava sus rabos en una zona pantanosa. Este cuento existe en la tradición actual -concretamente y en nuestra región, referido a Pedro Saputo- forma parte aquí de un cuento más largo en el que se nos relata distintas formas de cómo un criado consigue burlarse de su amo. De nuevo advertimos que la acción abstracta engañar se concreta en distintos modos de conseguir el engaño. La finalidad consiste en causar un daño al amo o a veces a otras personas sin causa justificada y evadirse de todo castigo. A este tipo corresponderían los cuentos de Till Eulenspiegel.

En el grupo «Cuentos y leyendas» Espinosa incluye tres cuentos: «¿Cuándo cegerá el mió Xuan?» (33), «El zapatero que cegó» (34) y «Xuan y Maruxa» (49) que nosotros consideraríamos del mismo tipo que el 198: «Xuan, Marica y el cura» al que Espinosa incluye dentro de su grupo «picarescos» en el subgrupo «Varios». Resulta increíble que la semejanza estructural de estos cuatro cuentos haya pasado desapercibida a Espinosa. Los cuatro presentan el clásico triángulo amoroso:

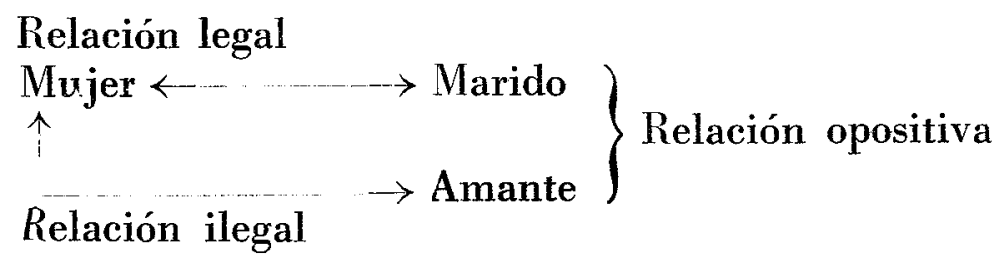

Amante y marido se hallan en una relación opositiva en tanto legal vs. ilegal. El engaño se consuma por la pérdida de visión (real o ficticia) del marido. En el cuento 198 Marica hace creer a su marido que desde lo alto de la higuera donde éste se halla, se sufre una alteración visual transitoria por la que los que está abajo aparecen en postura poco digna, valga el eufemismo. En el 49 el amante huye ocultándose tras una 
sábana que la suegra y la mujer tienden ante la vista del marido. En el 33 y 34 hallamos una situación de falseamiento de la realidad por parte del marido que hace pensar a su mujer y al cura que se ha quedado ciego. Mediante este engaño sorprende a los amantes y les infiere un severo correctivo. Se desprende del análisis de estos cuatro cuentos que pertenecen a un mismo grupo en el que encontramos una mala acción; en este caso se trata, como en los cuentos del Decamerón, del acto sexual sobre el que pesa una prohibición cualquiera siendo la situación más corriente la de la mujer que engaña a su marido. El medio de lograr los deseos no es el ocultamiento, sino la pérdida de visión del personaje que se opone a la consecución del deseo; esto intensifica el atrevimiento de los amantes. El castigo en este tipo de cuentos es generalmente evitado a pesar de transgredirse una ley social; digamos que la finalidad del cuento estriba ante todo en la manera ingeniosa de evitar el castigo más que en lograr el propósito. La adjunción del castigo, como aparece en los cuentos 33 y 34, parece ser fruto de un deseo moralizador añadido más tardiamente y obligado por las circunstancias.

Podríamos preguntarnos ahora si estos cuentos pertenecerían al mismo tipo de los antes citados en los que lo fundamental eran las burlas que el criado infería al amo. Evidentemente en ambos grupos se trata de un proceso semejante: engañar y evadir el castigo que sigue al engaño, si bien con fines distintos y en distinta relación opositiva. En el primero criado vs. amo en tanto humilde vs. poderoso. La mala acción del criado no implica castigo inmediato puesto que se evita mediante tretas o palabras ingeniosas. Se transgrede una ley social de sometimiento por parte del pobre pero ésta goza del favor popular y no conlleva el castigo. La burla supone una modificación en la situación y a veces tiene una finalidad objetiva: ganar una apuesta o demostrar la sabiduría ignorada de un personaje aparentemente necio. El segundo tipo de cuentos, en cambio, funciona en torno al eje del deseo sexual cuyo logro implica el engaño al oponente, en este caso representado por el marido. El tipo de relación que establece el deseo amoroso vincula a tres personajes, dos cómplices y un tercero paciente, que incluirían estos cuentos en un subgrupo dentro del grupo general.

Los cuentos del tipo «Pedro de Urdemales» reúnen una serie de elementos peculiares. Asi, los tres consejos que da el padre a los hijos están claramente relacionados con los cuentos 63-69, incluídos en el apartado «cuentos morales». La única diferencia estriba en que en éstos la objetivación de los consejos adquiere capital importancia hasta el punto de que constituye el núcleo narrativo del cuento, mientras que en los de Pedro el de Malas no pasa de ser una simple secuencia anecdótica y sin mayor importancia en la trama. Observamos la existencia de una conta- 
minación muy clara y que no aparece en otras versiones (164-167). Asimismo, el combate con el gigante parece estar vinculado con otros cuentos del tipo «Juan el Oso» y podría relacionarse con el 194 y 195 en que también se registra el enfrentamiento con un gigante o personaje de similares características, desarrollándose el encuentro en secuencias paralelas.

También están incluídos en el subgrupo Pedro de Urdemalas los cuentos correspondientes a Juan Soldao (168, 169), Juan Tonto (175) y la Muerte (171) en cuya estructura advertimos elementos maravillosos que nos hacen dudar de la inclusión de estos cuentos en el grupo «Picarescos». Existe un personaje donante que otorga un don al protagonista utilizado por éste en su lucha con el diablo o la muerte. El donante es Dios, que mantiene una relación opositiva con el diablo en tanto mal vs. bien. Probablemente la existencia de un donante Dios o Jesucristo sea muy posterior a otro tipo de donantes: una vieja, un animal, un hombre, etc., por las connotaciones religiosas estrechamente vinculadas al medio que implica el concepto de Dios. Existe, sin embargo, en estos cuentos una secuencia emparentada con los burlescos: Juan Soldao se come los riñones de un carnero y quiere hacer creer a sus compañeros (Dios y San Pedro) que dicho animal no tenía riñones. Tras algunas tentativas Dios desenmascara al mentiroso.

Otro apartado que Espinosa considera bajo la denominación de «picarescos» es el correspondiente a Juan Tonto. En el establecimiento de este subgrupo Espinosa tiene algunas reservas como él mismo hace notar en su estudio crítico: «A los tipos generales del verdadero pícaro se han mezclado en la tradición de Europa, y, particularmente en los países hispanoamericanos una variedad de cuentos en los cuales el protagonista es un tonto que se sale con la suya, interpretando las cosas literalmente» (p. 128). Realmente la definición del protagonista de estos cuentos no puede ser más inexacta, pues no sólo no «se sale siempre con la suya», sino que su comportamiento absurdo y estúpido es duramente castigado a veces incluso con la muerte, y ahí estriba la diferencia esencial con los cuentos burlescos. Los cuentos son una yuxtaposición de secuencias predicativas que confieren un contenido negativo al agente. Todas las secuencias nos muestran al personaje en cuestión haciendo lo contrario de lo que le dicen los demás, o de lo que convencionalmente está establecido: hasta aquí podríamos relacionarlo con los cuentos burlescos, pero mientras éstos poseen una evidente intencionalidad y pretenden el engaño, los del nuevo subgrupo se caracterizan por la opacidad total del personaje agente que no muestra ninguna intención engañosa activa, sino que es puro transpositor de la acción absurda en abstracto al acto personificado y que por ello adquiere mayor comicidad. Los verbos de estas secuencias son generalmente: estropear, perder, matar, es decir, representan todos ellos 
acciones de signos negativo inaceptadas por la sociedad y como tales comportan un castigo, rasgo que diferenciará estos cuentos de los propiamente burlescos. Juan Tonto es castigado por su oponente, generalmente la mujer o la madre y en algún caso fortuito por otros personajes. La necedad de Juan se opone a la inteligencia del contrario que a veces es intensificada mediante un nombre: María la Lista. Claro que esta pretendida inteligencia es sólo representación de las normas sociales establecidas; a partir de este personaje, el comportamiento del tonto adquiere verdadero relieve ya que se halla fuera de cualquier convencionalismo induciendo por esto a la comicidad. Efectivamente, es esto lo que se pretende: provocar la risa del oyente que a su ver está inmerso en el campo de actuación del oponente y desde su punto de vista observa la absurda conducta del tonto.

Simplificando lo que hasta aquí hemos considerado podrian establecerse tres esquemas paralelos para los tres tipos a los que integraríamos dentro del apartado «Burlescos». Prescindimos del subgrupo correspondiente al «Tonto y la princesa» por sus características vinculadas al cuento maravilloso. Igualmente eliminamos la subdivisión $b$ ), «Los dos compadres», porque los cuentos incluídos en ella no tienen un carácter claramente diferenciado, sino que se puede unir con los del grupo a). Los tres apartados que proponemos serían:

\begin{tabular}{lclll}
\hline \multicolumn{1}{c}{ Relación } & Ayudante & Acción & \multicolumn{1}{c}{ Objeto } & Castigo \\
\hline A. Amo vs. criado & $+/-$ & Engañar & $\begin{array}{l}\text { Ganar apuesta } \\
\text { Demostrar inte- } \\
\text { ligencia }\end{array}$ & - \\
B. Marido vs. & $+/-$ & $\begin{array}{l}\text { Engañar } \\
\text { Estropear } \\
\text { Romper... }\end{array}$ & Cómico & - \\
C. Listo vs. tonto & - & Deseo sexual & - \\
\hline
\end{tabular}

Proponemos con este esquema otros aspectos a tener en cuenta en una clasificación del cuento y abogamos por una revisión del modelo de Espinosa, que indudablemente presenta algunos fallos de los que sólo hemos señalado aquí los más evidentes. 
